\title{
Chapter 1. Precarious Labour and the Contemporary Novel
}

The focus of this book is on the condition that I call precarious labour. This term is intended not only to describe the conditions of work in the contemporary economy but also to signal something profound about the way that workers imagine their social relations in an era of endemic contingency and risk. In choosing to explore how this condition is made visible in contemporary fiction I follow a growing trend in literary criticism which has seen an increasing return to materialism in recent years. In the last decade, critics have demonstrated a renewed interest in literature as "an intervention" in the historical, political, and linguistic conjunctures of the present (Lecercle 2010). Yet, if there is a newfound wealth of economic and political literary-criticism, the question of work has been relatively under-examined. There are recent studies on the historical character of labour, especially in books on work and modernism (Godden 1997, Shiach 2003, Wild 2006) as well as books that seek to place contemporary labourpatterns within an historical context (Hapke 2001, Thompson 2003). Recently Michael Ross has examined the presentation of advertising work in literature (Ross 2015) but his focus is often on the craft of advertising or, in common with other criticism of this kind, on the corporation (Clare 2014) rather than on the presentation of work or workers. This rather small pool of critical writing is perhaps surprising given the prominence that work has in many people's lives and in the political cultures of contemporary society. Over the course of writing this book questions of work have frequently dominated the news cycle in the UK. Since 2007 unemployment rose to levels not seen since the recession of the 1980s, and real wages have fallen even as the labour market has recovered (OECD 2016, Office for National Statistics 2016). The disparity between wage and price inflation has led to campaigns for a "living wage" and to talk of a "cost-of-living crisis". Concerns about casualization, about the proliferation 
Precarious Labour and the Contemporary Novel

of unpaid internships and of "zero-hours contracts" have all made headlines. Paradoxically, a rise in part-time work has fuelled concerns about under-employment while problems of childcare-provision and extended working hours has placed the "work-life balance" onto the political agenda. Beneath all of this, the political vocabulary of "hard-working families" has repeatedly served as a moral index, used to justify cuts to government expenditure on services and welfare provision.

Irrespective of any topical features, the immediate political context for this book closely resembles the language about work that characterises the decades of what is best described as an era of flexible labour. Underpinning the present study, and justifying an attention to contemporary literature, is the claim that the conditions of work have changed since the late 1970s with significant implications for how work is understood. In the late 1970 and early 1980 s the taste for state intervention, which was the product of post-war Keynesianism, gave way to a new political orthodoxy that saw government as the facilitator of private-sector actors, who were best placed to improve productivity. When it came to work, the role of government was no longer to stimulate the economy and manage monetary policy to achieve high employment. Instead governments were to improve the efficiency of private employers by deregulating the labour market so that companies could better manage labour costs by more economically mapping employment onto demand. At the same time substantial changes to the kinds of work that was available were beginning to occur. The most obvious of these has been the clear growth in service-sector work since the late 1970s. The story of the major manufacturing economies of the Global North has been one of a substantial loss of manufacturing jobs. This was led by the twin processes of automation and of globalization, with many jobs moved overseas to low-income economies in the Global South. While this had immediate consequences for unemployment, it also saw the service sector grow to exploit the reserves of labour 
Precarious Labour and the Contemporary Novel

that these trends had produced. However, this trend is not limited to the traditional centres of manufacturing power; it is repeated in the new economic centres of the Global South. The World Bank estimates a 10\% increase in the proportion of GDP produced by service-sector work in the period between 1995 and 2014: in India this represents a $6 \%$ increase and in China, famed for its levels of manufacturing production, service-sector work accounts for over 14\% more of GDP than it did in 1995 (World Bank 2016). This is partly driven by technological innovation and the giant advances in telematics have resulted in a global proliferation of new kinds of clerical work.

The transformations of the work economy have had significant consequences for workers' relations to employment. At the most immediate level, the new regimes of flexible labour have had a negative effect on worker-security so, in the broadest terms, work histories are now "erratic and discontinuous rather than routine and determinate" (Sennett 2000, 183). The deregulation of employment has seen a decline in labour power in the form of trades unions, growing levels of unemployment, and increasing casualization with an increase in part-time and short-term contracts. One consequence has been to alter work-based identities that were rooted in occupation. Something similar follows from the rise in service work where the characteristics of office labour remains broadly similar from job to job. As Ursula Huws notes, the computerisation of large numbers of jobs has led to a flattening of occupational distinctions and the hollowing out of core skills, which are replaced by routinized or standardised forms of work (Huws 2000, 11-12). The issue of worker identity is key to the era of flexible labour because reform of the work economy has only been possible by workers absorbing and acquiescing to comparatively high levels of uncertainty. This involves a tension between the reality of work and the symbolic expectations that attach to it. Despite the daily realities of people's working lives, employment remains 
Precarious Labour and the Contemporary Novel

the only viable source of economic security and it is championed by neoliberal economics that insists upon self-sufficiency as a moral ideal. Work, and only work, is the route to the good life even if for many workers contingent and insecure employment cannot provide the better life that it promised.

This mismatch between the promise of success and the feelings of insecurity is key to the category of precarious labour that runs through this study. Undoubtedly, the experience of this failure in the contemporary era is hardened by a comparison with the decades of Keynesian economics that followed World War II. Contemporary workers can only look back jealously on post-war levels of employment, wage increases and social mobility. However, historically, the years of Keynesian economics were an aberrant golden age (Hatton and Boyer 2005). Consequently, what marks out the contemporary period is not simply growing levels of insecurity but rather an accompanying sense of loss for socialised forms of security that are recent in the memory but that no longer apply. This has profound implications for those in work who often feel vulnerable or precarious. Precarious labour does not only refer to the threat of unemployment, nor does it only cover conditions of work that are insufficient to secure the good life. Instead, the idea of precarious labour signals workers whose relationship to the social, whose very being, is contingent or at risk.

If work is a highly visible component of the social and political discourses, it is unsurprising that work features prominently in contemporary culture. This is demonstrably true in a range of popular cultural forms: even comic book superheroes, it seems, need to struggle to hold down a job in between catching villains. Despite their considerable differences, both the comic book Wanted and its movie adaptation (Bekmambetov 2008, Millar 2008) begin with a depiction of put-upon office worker Wesley Gibson suffering the travails of clerical work. The culmination of the film sees Wesley kill the corrupt head of an assassin's fraternity, before declaring that he is 
Precarious Labour and the Contemporary Novel

freeing himself from his line manager, from "billing reports" and "ergonomic keyboards". The desire to escape the mundane tedium and preposterous hierarchical pretentions of work is also excruciatingly played out in Ricky Gervais and Stephen Merchant's mockmentary The Office (2001-2003). Despite its knowing parody of the genre of reality television, the documentary-realism of its style prevents the possibilities of characters "taking control" in the melodramatic style of Wesley Gibson. The characters in Gervais and Merchant's series do not really progress and, tellingly, despite the plans to become graphic illustrators or return to college, they repeatedly defer these aspirations in favour of continuing work. The Office often uses the language of risk to justify the interminable everyday, with the character Tim preferring not to roll the dice rather than to risk something worse than his present life. Perhaps the most common cultural genre of work is the television advertisement. At any time of day television viewers are almost guaranteed to see people in offices. The threeminute segments between programmes offer depictions of smiling insurance sales staff ready to take the viewers' calls and promising to keep their best interests at heart. At other times the depiction of work invites viewers to imagine the TV workers as avatars of themselves. For instance, those advertisements that depict the joyful camaraderie of co-workers sharing sweet beverages or snack-food clearly seek to address the viewer in their own daily habitat. Alternately, television commercials represent a desire to escape work whether depicting the wily worker trying to outwit his employer to watch football and drink beer, or the bored long-suffering employee dreaming of escape to holiday locations or leisure pursuits.

With cultural texts of work so readily and incessantly available, the decision to limit the present book to a study of the novel might seem be perversely limiting. However, there are good reasons governing this choice. Certainly all the tropes of work that are visible in the fleeting nuggets of the television commercial are evident in the novel too. 
Precarious Labour and the Contemporary Novel

However, the novel may possess additional aesthetic features that allow these ideas to be more fully worked through. The length of novels as texts, the commitment of time that the writer is allowed to develop the story, characters or ideas, pushes past the condensed forms of much popular culture. Although the US treatment of The Office ran to nine seasons, with 188 episodes and nearly 70 hours of television, the novel is free from the serial crescendos of episodic narrative arcs that the television series demands. Formally, too, the novel offers something different still to film and television genres, which are more suited to action, or to dialogue, or to the silent, impressionist, limbic meaning of the image. Long stretched out meditations that would be tiresome on screen find a comfortable space in the novel that allows the text to develop conceptual ideas more immediately than its audio-visual counterparts. Nevertheless, the concentration on narrative fiction is partly driven by its concern with subjectivity and with character development. One of the features of the flexible economy has been the demand on individuals to manage their own "elective biographies" (Beck 200o, 166) or to "script" life-narratives in the same way as they might build a CV (Sennett 2000, 176). At the same time, the experience of living within these conditions, the feeling of uncertainty, is key to understanding what contingent flexibility might mean. As a literary form the novel is well suited to represent both these processes. The Bildungsroman, the key genre in the evolution of the novel, offers a genre for depicting characters' capacity or incapacity to shape a life in the modern workplace. Similarly, the novel of sensation and the Modern novel's inward turn have left formal legacies in the contemporary novel that allows it to explore the affective encounter with the regimes of flexible labour.

The main focus in this study is with novels that are set in an around offices. This is justified by the growth of service sector work and the growing immateriality of contemporary production. If office work is a global form of labour, the office novel is 
Precarious Labour and the Contemporary Novel

an increasingly common form in Anglophone writing. What is more, unlike other kinds of labour, office work often resembles the different kinds of cultural products that can depict it. This finds a mirror in the digitisation of clerical work, which leads the tasks of office labour to be duplicated in leisure activities. In Matt Thorne's Eight Minutes Idle, discussed in chapter 3, the narrator, Dan, whiles away the late shift playing a game called Hotel Babylon that simulates the leisure pursuits denied to him by his place at work but requires him to concentrate on his computer just as he would if he were working. While reading a novel potentially takes the reader away from work, it's notable that reading can emulate the tasks of work just as immediately as computerised leisure pursuits. Dan also fills the quiet hours in the office by reading books: he even trades a book with a co-worker for a copy of Hotel Babylon suggesting a certain equivalence if only in exchange. Reading at work also seems to be the main pursuit of the would-be novelist Hank Neary in Joshua Ferris' Then We Came to the End, discussed in chapter 4, and this is only possible because he photocopies books to disguise them as work. More tellingly, Stephen Shapiro has argued that the act of reading David Foster Wallace's The Pale King resembles the work that it depicts; turning the page of the novel is the exact duplicate of turning the pages of tax returns that the novel describes. Stylistically, too, the long flatly-repetitive descriptions of mind-numbing drudgery requires readers to battle their own boredom and constructs the task of reading as a kind of work (2014, 1268).

The growth of electronic books means that it is increasingly easy to read novels on a computer screen; at least as easy as it is to play games on one. If this leads novelreading to resemble other forms of popular culture, this is not surprising. The aesthetic mix of high art with pop culture was a trademark of postmodernism that was prevalent in the 1980 s and 1990s. However if the frivolous retreat from the "high seriousness of modernism" was one characteristic of the early postmodern art, 
Precarious Labour and the Contemporary Novel

contemporary literature seems to have regained a kind of earnestness that Fredric Jameson identifies as "political" but not "politics" (Baumbach, Young, and Yue 2016, 144). One feature of this shift has been a resurgence of literary realism that appears to be the main form of both popular and literary novels. Nonetheless, perhaps reflecting the fraught relationship between reality and representation that has haunted realism since its inception (Boxall 2015), contemporary realism cannot wholly escape the influence of modernism and postmodernism that were styled as alternatives to realism in the twentieth century. Stylistically the novels discussed in this book vary considerably; from the pulp-fiction genre writing of Chetan Bhagat's One Night @ Call Centre, to the ironic high postmodernism of Douglas Coupland's Generation X, to the fragmentary irrealism of David Foster Wallace's The Pale King. Characteristically, however, the individuals that make up the protagonists of these novels seem to be the constructs of pastiche, voluntarily constituting their personalities and life-narratives out of the fragments of the surrounding culture. Above all else, this takes as given the inessential nature of character, which is presented as the product of situated selfmaking rather than the authentic expression of the personality. Accordingly, the ubiquitous contemporary realism is a species of realism modified by postmodernism, which should be read as a mode of narration that bears the marks of postmodernity upon it. That is to say that, following Jameson, I want to read contemporary realism as a style of narration that is the product of the historical period of late capitalism in the same way as the earlier mode of postmodern fiction. This has certain methodological implications.

Throughout the study, I suggest that the novels are driven by an engagement with flexibility as the characteristic conditions of work in the contemporary period and that this generates various depictions of precariousness. However, the effort to turn this political awareness into a politics requires an act of interpretation that is able to 
Precarious Labour and the Contemporary Novel

connect the situations depicted in these novels to contemporary modes of production that are inscribed upon them. Although I often use the term critique in my reading of the novels that follow, it is important to be clear that this critique does not emerge immanently from the novels themselves. Any critique that these novels realise is only accessible through the act of reading them politically. To this end, I try to set the fictional accounts of work alongside a range of political theory about work that makes visible the relations between work and capital that govern the current labour economy. I take it as read that the novels and their readers know more than the characters that they depict. This is not simply to suggest that the fictional characters within the texts are naïve and unaware of the conditions that govern their lives. Rather it is to suggest that the text alone cannot make visible or generalise the conditions governing the characters relations to work and that this is only possible by reading the text theoretically. Reading the novels as texts about work and setting them against theories of worker relations allows a political economy to come into view. This also requires an act of comparison and in the chapters that follow I repeatedly suggest the value of reading across from one novel to another. This is particularly apparent in chapter 2 where I indicate the benefit of reading three of Douglas Coupland's novels as a single account of the post-Keynesian work economy. Yet, I want to underline too the value of reading between chapters to see repeating patterns and tropes of nostalgia, of the dislike of work, and of the difficulties and possibilities of solidarity between workers that co-exist within the text.

The book is divided into two sections: the first of these tries of offer an historical reading while the second suggests how this historical reading is spatially refracted by different national contexts and traditions. In the first two chapters I explore the broad changes to the conditions of employment during the era of flexibility since the late 1970s. In chapter 2 I read Douglas Coupland's Generation X (1991), Microserfs (2004) 
Precarious Labour and the Contemporary Novel

and JPod (2006) and examine how Coupland's generational narrative of declining worker compensation from the Baby-Boomer generation to the present day comes under pressure from reading these three novels as a novel-cycle. Although, individually, each novel is organised by nostalgia for the presumed security of earlier conditions of work, across the three novels Coupland depicts continuities between generations that undermine this narrative structure. What emerges from this reading is a modified narrative of presentism, whereby neither the past nor the future is accessible because, under capitalism, the past is consumed by indebtedness and access to the future is only imaginable as accumulation. In chapter 3, I read Matt Thorne's Eight Minutes Idle (1999) and David Szalay's London and the South East (2008) as examples of a genre that I call the precarity novel. Using the idea of precarity that emerges from the European left I consider how the experience of feeling precarious shapes the narrative form of these texts. This includes examining how work-based contingency extends to character's presentation of their own personality, forcing them to construct themselves as workers through various forms of fabricated selfcomposition. Similarly, these novels give an account of the structures of rationalisation through the subjective apprehension of the workplace: this includes feelings of paranoia generated by workplace surveillance and an experience of the regulation of time that is an obstacle to worker-agency or to narrative progression. Finally, these novels show how the structure of competition, essential to neoliberal philosophies, infects relations between workers. Competition excludes the possibility of workers coexisting within an assigned space or role and produces increasingly instrumental engagements between workers as well as limiting the possibilities for solidarity or class identity.

In section two, I group texts into different national case studies in order to compare how the general conditions of neoliberal labour form different meanings within 
Precarious Labour and the Contemporary Novel

different national traditions for thinking about work. In the first of these I read three US novels; Walter Kirn's Up in the Air ([2001] 2010), Joshua Ferris' Then We Came to the End (2007) and David Foster Wallace's The Pale King (2012); as novels about the incompatibility of persistent myths of American nationalism with neoliberal forms of office work. Using the idea of productive labour, I propose that these three novels establish a contrast between the feelings of being productive with the feelings of deathliness that arises from contemporary work. Beyond this, I argue, these three novels extend the idea of work as death to suggest that earlier Romantic notions of individualism are similarly destroyed by the new meaning for work as an expression of neoliberal forms of self-sufficiency. In chapter 5 I use a reading of Jenny Turner's The Brainstorm (2007) to explore how the idea of the working-woman can be situated within the continuation of neoliberal rationalisation under Britain's New Labour governments of the late 1990 and early-200os. Using the contested model of WelfareState collectivism as a frame of reference for understanding the composition of British society I suggest that Turner's novel transforms the generic expectations of women's popular fiction to stage a philosophical exploration of the concept of work. Turner's novel establishes Hegel's narrative of the master-slave dialectic as a potential allegorical structure for the novel but rejects its resolution in self-awareness. Instead, Turner moves towards the autonomist-Marxist idea of the refusal of work as a way to contend with the gendered division of labour and as a way to establish solidarity with other workers under the structure of socialised capitalism. In chapter 6 , I read across a range of Indian English-language novels to consider how Indian fiction has responded to the influx of capital in India's new Business Outsourcing Industry. I argue that the generational conflicts that appear to dominate Anglo-American novels about work take on a different status in India, where the post-war benefits of Keynesian economics did not emerge. Consequently, the rationalised pattern of neoliberal labour in India 
Precarious Labour and the Contemporary Novel

cannot be read as undoing the reformist advances of social capitalism as they are in novels from Britain or the USA. Instead an alternate narrative of generational differences emerges that is highly inflected by ideas of the nation as the repository of cultural tradition and by the relations to foreign capital. In the fictional accounts of call-centre work, novelists repeatedly return to the idea of imitation of western modernity as a frame for reading the young worker. This can be read variably as evidence of India's subordination to western capital, as proof of India's emergence as a global economy, and as the continuation of class-inequality within India's segregated economy. Finally, in chapter 7 , I note a gap in this study and turn to consider undocumented labour as the exemplary figure of precarity. Through a brief reading of Kiran Desai's The Inheritance of Loss (2006) and Monica Ali's In the Kitchen (2009), I sketch out potential methods for depicting undocumented labour as a site of political action. 